\title{
Carbon Footprint Calculation and Applied Research of Printing Enterprise Based on the ISO14064-1 Standard
}

\author{
Yongshuang Zhu ${ }^{1, *}$, Lijie Wang ${ }^{2}$ and An Chen ${ }^{3}$ \\ ${ }^{1}$ Xili Lake, Nanshan District, Shenzhen, Guangdong Province, P.R. China \\ ${ }^{2}$ Xili Lake, Nanshan District, Shenzhen, Guangdong Province, P.R. China \\ ${ }^{3}$ Pinghu,Longgang District, Shenzhen, Guangdong Province, P.R. China \\ ${ }^{*}$ Corresponding author
}

\begin{abstract}
Objective: This work was aimed to study carbon footprint calculation method of printing enterprise. Method: Carbon footprint calculation methods and procedures were studied based on ISO 14064-1 standard and the actual operations of printing enterprises. Carbon footprint of a specific printing enterprise in $\mathbf{2 0 1 5}$ was obtained. Result: Carbon footprint of the studied printing enterprise in 2015 was $25,879.35 t$, among which energy indirect emissions accounted for about 92\%, fixed combustion emissions accounted for $7.62 \%$, and mobile combustion emissions accounted for $\mathbf{0 . 3 9 \%}$. Conclusion: The main carbon emission sources of printing enterprise were energy indirect emissions and fuel combustion emissions. Indirect carbon emissions from electricity generation accounted for more than $90 \%$ and direct emissions from gasoline, diesel, natural gas and other fuel combustion accounted for less than $10 \%$.
\end{abstract}

Keywords- printing enterprise; carbon footprint; greenhouse gas emission

\section{INTRODUCTION}

To maintain the rapid economic development today, human beings are consuming more and more energy. As a result, the use of fossil energy dramatically increases the emission of carbon dioxide and other greenhouse gases, and the greenhouse effect has become a serious problem facing the international community. In 2007, the UN's International Panel on Climate Change (IPCC) released an assessment report pointing out that more than $90 \%$ global climate anomalies may be caused by emission of greenhouse gases [1]. Greenhouse gases generally include six types of gases: carbon dioxide $\left(\mathrm{CO}_{2}\right)$, methane $\left(\mathrm{CH}_{4}\right)$, nitrous oxide $\left(\mathrm{N}_{2} \mathrm{O}\right)$, hydrofluorocarbons (HFCs), perfluorocarbon (PFCs) and sulfur hexafluoride (SF6) [2]. All their contribution to the greenhouse effect can be represented with carbon dioxide $\left(\mathrm{CO}_{2}\right)$ equivalent, referred to as "carbon emission" or "carbon footprint" for short [3].

According to the relevant data, the human activity around the world has generated up to 36 billion tons of carbon emission in 2013, 5 tons of carbon dioxide emission per capita, setting a new record, among which the carbon emission in China accounts for the largest share of 29\%, 7.2 tons per capita. China's carbon emission per capita has surpassed that of Europe for the first time [4]. Faced with the threat of global warming and environment worsening, carbon footprint has become a hot spot of research in China and abroad in recent years. The carbon emission involves different aspects of state agencies, enterprises (organizations), products and services. The Chinese government has been committed to reducing the carbon emission intensity per unit of GDP in 2020 by $40 \%$ $50 \%$ compared with that in 2005 [5] at national level. Therefore, different industries and enterprises are also actively seeking for green growth with low carbon emission. The printing industry is ranked in the list of high energy consumption and pollution industries in some regions and provinces, but in fact, the relevant environmental statistics data are still absent in printing industry as in packaging industry [6]. So for the printing industry, to understand the "carbon emission" in the industry and put forward quantitative indicators for low carbon economy through calculating the "carbon footprint" of enterprises are quite important to improving the environmental protection of the enterprises and the industry, as well as to promoting low-carbon development of the industry.

At the beginning of 2013, the pilot carbon trading schemes were launched in seven provinces and cities in China including Guangdong, Hubei, Beijing, Shanghai, Tianjin, Shenzhen and Chongqing. Plans were made to issue the "Regulations on the administration of carbon emission trading" and detailed rules for implementation on the basis of summarizing the above pilot carbon trading schemes, form the corporate greenhouse gas emission reporting system and initiate the national carbon trading market in 2017 [7] when the domestic enterprises can participate in local or national carbon trading.

The international organization for standardization (ISO) has published three international standards for quantification and verification of greenhouse gases at different levels [8]. The standard at the first level is the ISO 14064 standard comprising three parts, respectively for the quantification and reporting of greenhouse gases at the organization level and project level, and review and verification of report. The standard at the second level is the ISO 14065 standard, specifying provisions on the certification bodies. The standard at the third level is the ISO 14067 standard, putting forward the requirements on quantification and communication of product carbon footprint. 
ISO14064-1 standardizes the quantification and reporting requirements of greenhouse gas emission and elimination at the organization level, based on which this paper analyzes the carbon emission sources in printing enterprises and studies the methods and steps of carbon footprint calculation considering the specific operations of printing enterprises. The results are intended to be applied to printing enterprises to calculate the carbon footprint in specific printing enterprise, aiming to provide reference for carbon footprint calculation of domestic printing enterprises.

\section{DEFINITION OF CARBON FoOTPRINT CALCULATION OF PRINTING ENTERPRISE}

Carbon footprint refers to the greenhouse gas emission generated by an individual, a particular activity or organization, calculated on the basis of $\mathrm{CO}_{2}$ equivalent, which is a method used to by each organization or individual to evaluate contribution of greenhouse gas emission to climate change [9]. Carbon footprint can be divided into three levels including personal carbon footprint, product/enterprise carbon footprint and national carbon footprint in the aspect of application [10]. The product carbon footprint here refers to the carbon emission produced in fuel consumption and generation calculated in the exploitation of raw materials, production, transportation, manufacturing, consumption and eventual scrapping phase. The enterprise carbon footprint is different from the product carbon footprint, which means the carbon emission calculated in the organizational boundaries in the process of a certain period of operation time, excluding the carbon emission in exploitation of raw and auxiliary materials, production and transportation, as well as the carbon emission generated after the products are delivered to the customer. The enterprise carbon footprint of printing enterprise refers to all carbon emission of a printing enterprise in the production process, operating activities, transportation within the operation boundaries and within a certain period of time, excluding the carbon emission produced in the production and transportation of raw and auxiliary materials, transportation and distribution of finished products, and product scrapping.

\section{CARbon Footprint CALCUlation Method OF PRINTING ENTERPRISE}

There are three methods for calculating the carbon footprint of printing enterprise: measurement approach, mass balance approach and emission factor approach[11]. Measurement approach is to obtain the greenhouse gas emission data through direct monitoring and measurement using instruments or calculation, usually with the direct measuring instrument of greenhouse gas emission, which is used in enterprises with direct emission of greenhouse gases in the process of operation. Mass balance approach is used for calculating greenhouse gas emission generated in some chemical reactions involving the production, consumption and transformation of quality and energy of the materials in some enterprises, such as cement manufacturers. Emission factor approach is to calculate the carbon footprint through multiplying the active data of greenhouse gas emission source and emission factors.
Within the operation boundary of printing enterprise, the quantity of greenhouse gas directly discharged is little, only including the greenhouse gases generated by running airconditioning or waste gas, waste liquid treatment, which account for a low proportion of total greenhouse gas emission, so it is not suitable to select the measurement approach. Chemical reaction is relatively rare in the production of printing enterprise, so the carbon emission mainly comes from the purchased electric power and fuel, therefore the mass balance approach is not applicable, and the most appropriate method is emission factor approach.

The computation equation of emission factor approach is as follows:

\section{Carbon footprint $=$ Active data $\mathrm{x}$ Emission factor}

The calculation equation of carbon footprint of printing enterprise is as follows:

$$
\mathrm{Y}=\Sigma_{\mathrm{i}} \mathrm{X}_{\mathrm{i}}
$$

Where, $Y$ refers to the total carbon footprint of printing enterprise in a certain time boundary; i refers to the carbon emission source; $X_{i}$ refers to the carbon footprint of the ith carbon emission source.

$X_{\mathrm{i}}$ is obtained through the calculating equation of emission factor approach, namely:

$$
\mathrm{X}_{\mathrm{i}}=\mathrm{N}_{\mathrm{i}} \beta_{\mathrm{i}}
$$

Where, $N_{\mathrm{i}}$ refers to the active data of the ith carbon emission source; $\beta_{\mathrm{i}}$ refers to the emission factor of the ith carbon emission source.

\section{CARBOn FoOtPRINT CALCULATION STEPS OF PRINTING ENTERPRISE}

The carbon footprint calculation steps of printing enterprise are shown in Figure 1:

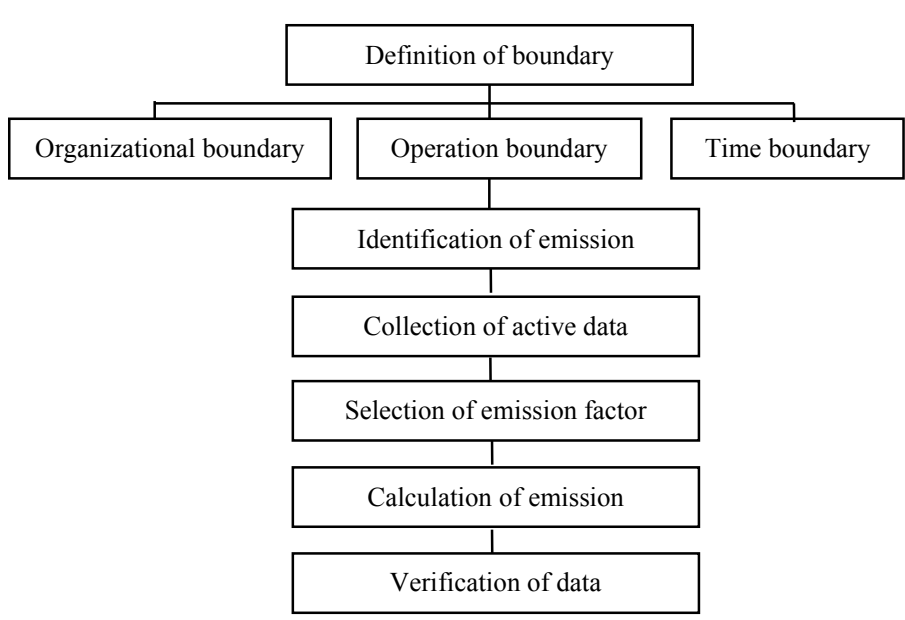

FIGURE I. CARBON FOOTPRINT CALCULATION FLOWCHART OF PRINTING ENTERPRISE 


\section{A. Definition of Boundary}

Boundaries shall be defined based on the purpose and scope of carbon footprint research. The enterprise boundaries include organizational boundary and operation boundary.

Organizational boundary: It is defined by the enterprise based on the target of carbon emission examination for calculating the carbon footprint, which can be a group comprising more than one enterprise, one single enterprise, or a department, but shall include all the facilities that can be controlled in the aspects of finance or operation within the organizational boundary. The printing enterprises are generally equipped with facilities including pre-press equipment, printing equipment, post-press equipment, other production equipment, drying equipment, ventilation equipment, lighting equipment, building heating or cooling equipment, humidity regulator, and other equipment.

Operation boundary: It defines the scope of all activities including production or service operations for calculating carbon footprint of printing enterprise, including design, graphic production, plate making, printing, post-press processing, delivery service, sales and customer service. The definition of operation boundary includes the identification of carbon emission sources and elimination sources related to enterprise operation, which can be classified according to whether it is direct emission or indirect emission. The indirect emission can be divided into indirect emission from energy and other indirect emission [11].

To calculate carbon footprint of enterprises, in addition to enterprise boundaries, the time boundary shall also be defined, which refers to the reference week, month, quarter or year used to verify the greenhouse gas emission in the carbon footprint calculation.

\section{B. Identification of Carbon Emission Sources}

The carbon emission in printing enterprise has two categories: direct carbon emission and indirect carbon emission.

a) Direct carbon emission. The direct carbon emission (category 1) includes four aspects: emission from fixed combustion, emission from mobile combustion, fugitive emission and emission from production process. The direct carbon emission in printing enterprise include emission from fixed combustion, such as greenhouse gas emission generated from the electric power, heat, steam or other energy generation; emission from mobile combustion, such as greenhouse gas emission generated in the transportation of raw materials, products, and solid waste owned or controlled by the enterprise, as well as employee commuting; fugitive emission, referring to intentional or unintentional discharge, including leakage from equipment joints, dissipation of cooling media from refrigeration equipment, greenhouse gas emission in sewage and waste gas treatment; emission from production process, referring to the greenhouse gas emission in the biological, physical or chemical processes, which is rarely seen in the production process of printing enterprises.

Some gases may be generated in the production process of printing enterprise, such as volatile organic gas (VOCs) vaporized from fountain solution, printing ink, adhesives and cleaning agents. The gases vaporized in lithography printing process include isopropyl alcohol and n-heptane; gases vaporized in gravure printing process include ethyl acetate, toluene and butanone; the gas vaporized in embossed printing process is toluene [12]. In the printing enterprise using UV ink or UV varnish, ozone $\left(\mathrm{O}_{3}\right)$ is discharged, which can raise the earth's temperature. But because ozone is not included in the six greenhouse gases listed by IPCC for one hundred year's time, and the above VOCs are not also included in them, they shall not be classified as fugitive emission.

b) Indirect carbon emission. The indirect emission includes two aspects: indirect emission from energy (category 2) and other indirect emission (category 3 ). Indirect emission from energy refers to the indirect emission of greenhouse gases produced in the generation of electric power, heating, cooling or steam from external, which shall be purchased by the enterprise instead of being produced by the enterprises, but they shall be quantified. According to the ISO14064 standard, the other indirect emission generated in purchased processing, employee's business trips and waste transportation shall either be included in the enterprise carbon footprint as an option or not included.

The carbon emission sources in printing enterprise are shown in Figure 2.

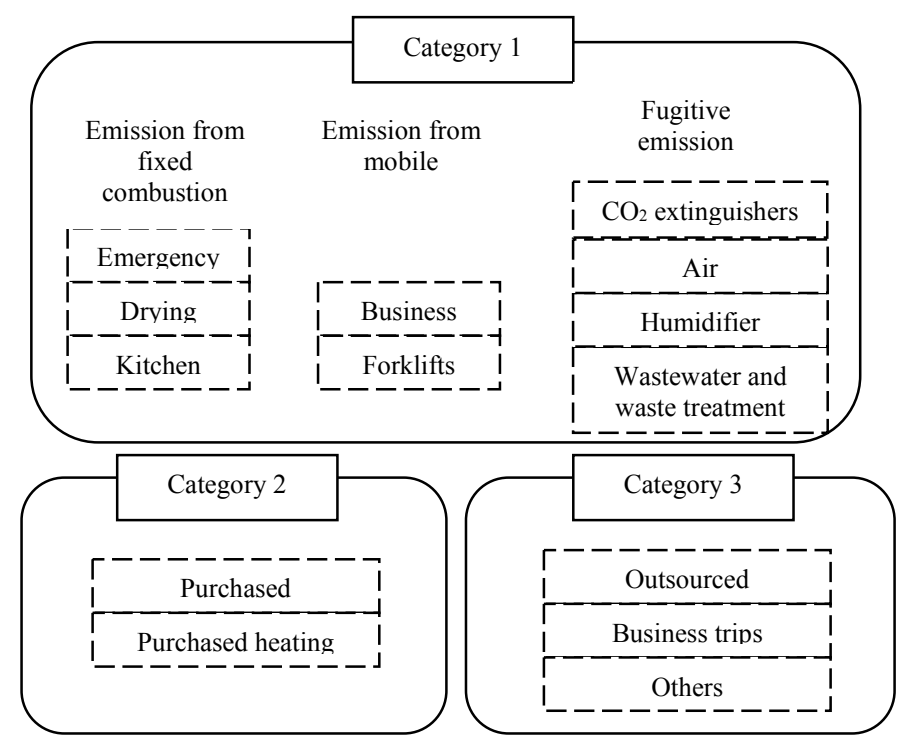

FIGURE II. GREENHOUSE GAS EMISSION SOURCE DIAGRAM OF PRINTING ENTERPRISE

The carbon emission of printing enterprise mainly comes from the indirect carbon emission from energy, namely the greenhouse gas emission produced in the production of purchased electric power and heating. In the direct carbon emission sources of printing enterprise, the emission from fixed combustion mainly comes from fuel burning of the drying equipment; the emission from mobile combustion mainly comes from the fuel combustion of vehicles transporting internal goods and employee commuter vehicles; fugitive emission mainly refers to the refrigerant escaping 
from air conditioning equipment and greenhouse gases escaping in the process of wastewater, waste gas treatment.

\section{Collection of Active Data}

Active data can be collected through analysis and identification of carbon emission sources in the printing enterprises. According to the requirements of ISO14064-1 standard, the direct or indirect sources of greenhouse gas emission that have insignificant effect on greenhouse gas emission, or whose quantification is technically unfeasible, or which results in high cost but little effect can be ruled out [11]. For example, the fugitive emission in category 1 and emission in category 3 of Figure 2 are technically unfeasible to be quantified for printing enterprises and their emission effect is not obvious, and can be excluded from the calculation except those that can be technically quantified.

Mainly active data of carbon sources in printing enterprise are shown in the Table 1 below:

TABLE I. MAINLY ACTIVE DATA COLLECTION FORM OF PRINTING ENTERPRISE

\begin{tabular}{|l|l|l|}
\hline \multicolumn{2}{|c|}{ Emission category } & \multicolumn{1}{c|}{ Emission source } \\
\hline $\begin{array}{l}\text { Direct } \begin{array}{l}\text { Earbon } \\
\text { emission }\end{array} \\
\text { fixed } \\
\text { combustion }\end{array}$ & $\begin{array}{l}\text { Natural gas: drying devices of commercial } \\
\text { rotary printing press }\end{array}$ \\
\cline { 2 - 3 } & $\begin{array}{l}\text { Emission from } \\
\text { mobile fuel } \\
\text { combustion }\end{array}$ & $\begin{array}{l}\text { Diesel generator } \\
\text { for internal transportation of goods and } \\
\text { employee commuter vehicles }\end{array}$ \\
\hline \multicolumn{2}{|l|}{ Indirect carbon emission } & $\begin{array}{l}\text { Purchased electric power: power supply to } \\
\text { all equipment and factory lighting }\end{array}$ \\
\hline
\end{tabular}

\section{Selection of Emission Factor}

Emission factors include international emission factors, such as the emission factors publicized by IPCC, national emission factors and regional emission factors, emission factors provided by the equipment manufacturers, emission factor acquired based on work experience and evidence with the same process or equipment and the emission factors obtained through measurement and calculation [13]. As the carbon emission of printing enterprises is mainly from the electric power and fuels they consume, the emission factor of electric power shall be the regional emission factor.

\section{E. Calculation of Emission}

The greenhouse gas emission of printing enterprises shall be calculated with the method of carbon footprint calculation in Chapter II, and the calculation result shall be expressed in tons of carbon dioxide equivalent ( $\mathrm{tCO} 2 \mathrm{e})$.

\section{F. Verification of Data}

In the process of greenhouse gas quantification, the data shall be verified; the completeness and correctness of the active data shall be checked; the influence on active data of different statistical methods shall be analyzed; the rationality and timeliness of the emission factor shall be confirmed; the correctness of the units and conversion of emission factors shall be verified; the correctness of the calculation results shall be checked by comparison with historical data.

\section{INSTANCES OF CARBON FOOTPRINT CALCULATION OF PRINTING ENTERPRISE}

\section{A. Objectives of Research}

The carbon emission within the time boundary of 2015 shall be calculated with the above calculation method and steps through analysis, research and data tracking of the actual printing enterprises, analysis of all carbon emission factors within the organization boundary and operation boundary.

\section{B. Research Object}

The research object is a large enterprise in Shenzhen specialized in business and book printing. The enterprise is equipped with production equipment including pre-press equipment such as pre-press graphic processing computers, direct plate maker and digital proofing machine, and postpress equipment including lithographic offset printing presses and commercial offset printing presses, binding line, hardcover production line, staple production line, folding machine, sewing machine, laminating machine and die-cutting machine.

\section{Greenhouse Gas Emission Sources}

Through screening and analysis of organizational boundary and operation boundary of the enterprise, the main emission sources of greenhouse gases of this enterprise are identified as shown in Table 2.

TABLE II. GREENHOUSE GAS EMISSION SOURCE INSTANCE OF PRINTING ENTERPRISE

\begin{tabular}{|c|c|c|}
\hline $\begin{array}{l}\text { Emission } \\
\text { category }\end{array}$ & Emission sources & Active data \\
\hline \multirow[t]{2}{*}{$\begin{array}{l}\text { Direct carbon } \\
\text { emission }\end{array}$} & $\begin{array}{l}\text { Natural gas or coal gas } \\
\text { (emission from fixed } \\
\text { combustion) }\end{array}$ & $\begin{array}{l}\text { Quantity of gas consumed } \\
\text { within the time boundary }\end{array}$ \\
\hline & $\begin{array}{l}\text { Fuels of transportation } \\
\text { equipment (emission from } \\
\text { mobile fuel combustion) }\end{array}$ & $\begin{array}{l}\text { Quantity of fuel consumed } \\
\text { within the time boundary }\end{array}$ \\
\hline $\begin{array}{l}\text { Indirect } \\
\text { carbon } \\
\text { emission }\end{array}$ & $\begin{array}{l}\text { Purchased electric power, } \\
\text { heating, cooling and steam }\end{array}$ & $\begin{array}{l}\text { Quantity of electric power } \\
\text { and other energies } \\
\text { consumed within the time } \\
\text { boundary }\end{array}$ \\
\hline
\end{tabular}

D. Data Collection and Carbon Footprint Calculation0

In the above instance, the fuel and electric power data are acquired from the statistical data of the enterprise. The carbon emission of this enterprise in 2015 is calculated as shown in Table 3: 
TABLE III. EXAMPLE OF DATA COLLECTION AND CARBON FOOTPRINT CALCULATION

\begin{tabular}{|c|c|c|c|}
\hline $\begin{array}{c}\text { Emission } \\
\text { source }\end{array}$ & Consumption & 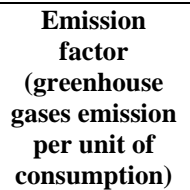 & $\begin{array}{l}\text { Greenhouse } \\
\text { gas emission } \\
\text { (carbon } \\
\text { dioxide } \\
\text { equivalent) }\end{array}$ \\
\hline Natural gas & $865,404 \mathrm{~m} 3$ & $\begin{array}{r}0.0022[13] \\
\mathrm{tCO} 2 / \mathrm{m} 3\end{array}$ & $1,903.89 \mathrm{t}$ \\
\hline $\begin{array}{l}\text { Diesel } \\
\text { (generator) }\end{array}$ & $21,882 \mathrm{~kg}$ & $3.10[13] \mathrm{tCO} 2 / \mathrm{t}$ & $67.83 \mathrm{t}$ \\
\hline $\begin{array}{l}\text { Diesel } \\
\text { (transportation } \\
\text { vehicles) }\end{array}$ & $1,370 \mathrm{~kg}$ & $3.10[13] \mathrm{tCO} 2 / \mathrm{t}$ & $4.25 \mathrm{t}$ \\
\hline $\begin{array}{l}\text { Gasoline } \\
\text { (transportation } \\
\text { vehicles) }\end{array}$ & $33,322 \mathrm{~kg}$ & $2.92[13] \mathrm{tCO} 2 / \mathrm{t}$ & $97.30 \mathrm{t}$ \\
\hline Electric power & $25,924,080 \mathrm{kwh}$ & $\begin{array}{l}0.9183[14] \\
\text { tCO2/mwh }\end{array}$ & $23,806.08 \mathrm{t}$ \\
\hline \multicolumn{3}{|l|}{ Total } & $25,879.35 \mathrm{t}$ \\
\hline
\end{tabular}

The emission factor of electric power in Table 3 is for 2014, and the data for 2015 has not yet been released by the state.

\section{E. Results and Data Analysis}

In the case above, the proportions of the greenhouse gas from all emission sources in the total emission of the enterprise are shown in Table 4, and the largest proportion is the indirect emission of electric power, accounting for $91.99 \%$ of total emission; while the proportion of emission from mobile combustion is rather small, only accounting for $0.39 \%$ of total emission. Carbon footprint of printing enterprise for each emission source.

\section{TABLE IV. CARBON FOOTPRINT OF PRINTING ENTERPRISE FOR} EACH EMISSION SOURC

\begin{tabular}{|c|c|c|}
\hline Emission source & $\begin{array}{c}\text { Carbon footprint } \mathrm{CO} 2 \\
\text { equivalent }(\mathrm{t})\end{array}$ & Proportion \\
\hline $\begin{array}{lll}\begin{array}{l}\text { Emission } \\
\text { combustion }\end{array} & \text { from } & \text { fixed } \\
\end{array}$ & 1971.72 & $7.62 \%$ \\
\hline $\begin{array}{lll}\begin{array}{l}\text { Emission } \\
\text { combustion }\end{array} & \text { from mobile } \\
\end{array}$ & 101.55 & $0.39 \%$ \\
\hline $\begin{array}{l}\text { Indirect carbon emission } \\
\text { from energy }\end{array}$ & $23,806.08$ & $91.99 \%$ \\
\hline Total & $25,879.35$ & $100 \%$ \\
\hline
\end{tabular}

From the above data, the carbon emission of printing enterprise is mainly from electric power, which means that reducing electric power consumption is the key for the printing enterprise to reduce carbon emission. The printing enterprise can improve energy efficiency by optimizing the compressed air equipment, adjusting motor revolutions, adopting highefficiency air humidifying technology, optimizing heating equipment, using state-of-the-art lighting technology, lighting management, intelligent control and regulation technology, and performing peak load management and heat recovery. According to the investigation of energy efficiency consultant Jürgen Bühler, for the printing enterprise of size between 3 and 250 employees, the average potential energy conservation in $\mathrm{KWH}$ can reach $25 \%$ [15], which means that there is large room for energy saving in the printing enterprise, representing great potential in reduction of carbon emission.

\section{CONCLUSION}

The carbon footprint calculation of printing enterprise provides basis for realizing carbon trading of printing enterprises, which is rather important for low carbon development of enterprise and industry.

The carbon footprint calculation of printing enterprise includes the carbon emission in the process of production, operation and service activities within the organizational boundary of an enterprise within a certain period of time, excluding the carbon emission in production and transportation of raw and auxiliary materials, distribution of finished products.

The direct carbon emission of printing enterprise comes from the fuels consumed by generators, drying equipment and transport vehicles. The fugitive emission is difficult to measure and contains little greenhouse gas, which is negligible, so the carbon emission of largest proportion of printing enterprise is the indirect carbon emission from energy, namely the greenhouse gas emission from electric power generation.

For printing enterprises, the key to reducing carbon emission is to save electric power, such as use of energysaving equipment, energy-saving lighting, reasonable arrangement of production to improve production efficiency.

Though in the instance above, the printing enterprise mainly adopts offset lithography, the method and conclusions in this paper can be applied to printing enterprises adopting gravure printing, flexographic printing, digital printing or other ways of printing.

\section{REFERENCES}

[1] IPCC. Climate Change 2007: The Physical Science Basis[EB/OL].[2010-07-19].http://www.ipcc.ch.

[2] United Nations Framework Convention on Climate Change [EB/OL].[2010-07-

19].http://unfccc.int/resource/docs/convkp/kpchinese.pdf.

[3] ISO 16759 Graphic technology - Quantification and communication for calculating the carbon footprint of print media products [2013-07-01].

[4] 2013 data of global carbon emission released, and for the first time Chinese per capita is over European counterpart [EB/OL]. [2014-0923].http://finance.huanqiu.com/view/2014-09/5146643.html.

[5] National Climate Change Programme of China [EB/OL]. [2007-06-11]. http://www1.chinaccm.com/30/3027/302702/news/20070611/132937.as p.

[6] Zongyi Hu, Yiwen Liu, Yu Dai. On Necessity and Countermeasures of Carbon Emissions Statistics in Low-carbon Packaging Industry[J]. Packaging Engineering, 2012 (9) :136-140.

[7] A unified national carbon market will be founded in 2017[EB/OL]. [2016-03-23]. http://www.tanpaifang.com/tanjiaoyi/2016/0323/51599.html.

[8] Liang Chen, ling Lin,Baowei, Jianhua Chen.Management Standardization Progress Review of Domestic and International Carbon Mmission [J]. Energy of China, 2014 (1) :24-28.

[9] PAS 2050:2008.Specification for the Assessment of the Life Cycle Greenhouse Gas Emissions of Goods and Services[S].London:British Standards Institution,2008.

[10] Kenny T,Gray N F. Comparative performance of six carbon footprint models for use in Ireland[J]. Environmental Impact Assessment Review, 2009(29):1-6. 
[11] ISO14064-1 Greenhouse gases - Part 1: Specification with guidance at the organization level for quantification and reporting of greenhouse gas emission and removal.

[12] Yang Yang, Jing Yang, Shasha Yin, Yufan Yu, Junyu Zheng, Ziwei Mo.Speciated VOCs Emission Inventory and Key Species from Printing Industry in the Pearl River Delta Region[J].Research of Environmental Sciences,2013,26 (3) :326-332.

[13] Market and Quality Supervision Commission of Shenzhen Municipality. SZDB/Z 69-2012, Organizational Green House Gas Emission Quantization and Report Standard and Guidance [S].

[14] Shenzhen: Market and Quality Supervision Commission of Shenzhen Municipality, 2012 [14]2014 China's regional power grid baseline emission factor [ $\mathrm{EB} / \mathrm{OL}]$ http://wenku.baidu.com/link?url=HaTmbPwhuJNFQGepaEuES2tgXq52 slJkl3Fze6_B2TUe7_rl_nV1lcsZFMG3Yo_nUDnnmWanJKqLeXintfI5 w0Tfc4pb6QXpIG2h- $9 \overline{\mathrm{N}} 8$-zqu.

[15] Shiheng $\mathrm{Xu}$. Green Printing Experience of Printing Companies from Germany[J]. Printing Technology, 2016(01):30-31. 